\title{
Detection of Fungi Infecting Maize (Zea mays L.) Seeds in Different Storages Around Jimma, Southwestern Ethiopia
}

\author{
Binyam Tsedaley ${ }^{1^{*}}$ and Girma Adugna ${ }^{2}$ \\ ${ }^{1}$ College of Agriculture and Natural Resource, Assosa University, PO Box 18, Assosa, Ethiopia \\ ${ }^{2}$ College of Agriculture and Veterinary Medicine, Jimma University, PO Box 307, Jimma, Ethiopia
}

*Corresponding author: Binyam Tsedaley, College of Agriculture and Natural Resource, Assosa University, PO Box 18, Assosa, Ethiopia, Tel: +2510576690809; E-mail: binyamtsedaley@gmail.com

Rec date: March 01, 2016; Acc date: March 23, 2016; Pub date: March 26, 2016

Copyright: ( 2016 Tsedaley B, et al. This is an open-access article distributed under the terms of the Creative Commons Attribution License, which permits unrestricted use, distribution, and reproduction in any medium, provided the original author and source are credited.

\begin{abstract}
Maize is attacked by more than sixty diseases and a number of species of insect pests in the field as well as in the storage. Fungi are among the principal causes of deterioration and yield loss on farmers' maize during the storage period. Among the storage fungal pathogens Aspergillus, Fusarium and Penicillium are the most predominant species attacking maize seed and resulting in reduction in seed germination. The study was conducted at the Jimma University College of Agriculture and Veterinary Medicine in plant pathology laboratory. Three maize varieties and two levels of disinfection were used and arranged in complete block design with five replications. The highest frequency of Aspregilus spp. (40.4\%) at farmer preserved seed with surface disinfected kernels on agar plate were recorded. The highest relative density of Fusarium spp. (51\%) was only recorded on agar plate test from the farmer preserved seed without. The lowest germination percentage $(62 \%)$ were recorded on the farmer preserved seed which was not disinfected. The Aspregilus spp. are the most dominant fungi followed by Fusarium spp. isolated in this study as well as in Ethiopia. These fungi are important in producing secondary metabolites which are carcinogenic to both humans and animals.
\end{abstract}

Keywords: Aspergillus; Fungi; Fusarium; Penicillium; Seed germination

\section{Introduction}

Maize is the third most important food crop in the world surpassed only by two other grains, wheat and rice $[1,2]$. The growing demand for food consumption in developing countries alone is predicted to increase by around $1.3 \%$ per annum until 2020 [3]. By 2050 demand for maize will double in the developing world, and maize is predicted to become the crop with the greatest production globally, and in the developing world by 2025 [4]. In Ethiopia maize is the first most important cereal crop in terms of its production accounting for $26.7 \%$ (7.2 million tons) of $87.3 \%$ ( 23.6 million tons) of the cereal production [5]. However, around 47 maize diseases were recorded in maize and 25 more diseases were recorded in the past few years which are the major limiting factors of its production in Ethiopia [6]. From these disease gray leaf spot, Turcicum leaf blight, leaf spot, common leaf rust, eyespot, brown spot, streak virus, and storage disease caused by Fusarium spp and Aspergilus flavies are the major maize disease in Ethiopia [7]. Maize cultivation in the world is limited by diseases which cause grain loss of about $11 \%$ of the total production [8]. Fungi are among the principal causes of deterioration and loss of maize grain [9]. Kossou and Aho [10] reported that fungi could cause about $50-80 \%$ of damage on farmers' maize during the storage period if conditions are favorable for their development.

During storage, several kinds of fungi can remain associated to maize seeds either causing their deterioration or simply remain viable to infect germinating seedling. The fungi genera typically found in stored grains are Aspergillus, Penicillium, Fusarium [11,12] and some xerophytic species, several of them with capabilities of producing toxins [12]. The development of these fungi can be affected by moisture content of the product [13]. Temperature, storage time and degree of fungal contamination prior to storage, insect and mite activity facilitate fungi dissemination [8]. There is a general increase in consumption of contaminated grain with mycotoxins which causes different health problems including death $[14,15]$. The rank of fungi is second after insects as the cause of deterioration and loss of maize [16]. Aspergillus flavus becomes systemic and produces aflatoxin and vivesces in seedling of maize and damage stored corn. Fusarium invade more than $50 \%$ of maize grain before harvest and produce mycotoxin [16], while Aspergillus flavus is a food contaminant and capable of producing aflatoxin [17].

In Ethiopia various grain mold fungi including Fusarium, Penicillim, and Aspergillus, Nigropora spp. have been detected on maize samples collected from Hawassa, Areka, Billito, Shallo and ArsiNegele. The populations of all the fungi were higher in samples collected from farmers' stores than in the samples collected from research and seed multiplication stores [7]. Aspergillus and Fusarium were frequently isolated from damaged seeds and Penicillim spp. were the second most frequent fungal species. Wubet and Abate [18] also identified four Fusarium species associated with maize grain in Ethiopia. The presence of mycotoxins in grains and other staple foods and feedstuffs $[19,20]$ has serious implications for human and animal health and reduce seed quality by discoloration of the seeds. Food security is recognized as one of the main challenges in the droughtprone areas of Eastern Africa where seed insecurity is a major factor contributing to food insecurity. In the drought-prone areas of Ethiopia, seed insecurity contributes a great deal to the inefficiency of the agricultural sector [21]. Despite the prevalence and seriousness of these storage fungi causing losses to the seed of maize crop in the stored in Ethiopia, adequate studies have not been made. Information 
on detection of these fungi is limitedly available. Hence much remains to be done on the detection of storage maize seed fungal pathogens are required. The present study was initiated with the objective detection of fungi infecting maize seeds in different storages around Jimma, Southwestern Ethiopia.

\section{Material and Methods}

\section{Study area}

The study was conducted at Jimma University College of Agriculture and Veterinary Medicine in the plant pathology laboratory in 2014. The experimental site is located at 350 kilometers from Addis Ababa, at $36^{\circ} 50^{\prime}$ East longitude, $7^{\circ} 40^{\prime}$ North latitude and at an altitude of 1,740 meters above sea level. It is situated in the mid-altitude tropical belt of south-western Ethiopia.

\section{Experimental materials, treatments and design}

This experiment was designed to isolate fungal pathogens associated on stored maize grain of different varieties with surface disinfecting and without disinfecting. The sample seeds of the varieties were collected one variety (Melko), from Jimma Agricultural Research Center, one Chemically treated with seed dressants (fungicide plus insecticide), with moisture content of $12.5 \%$, germination (97\%) and purity of $98 \%$ variety (BH660) from Jimma Zone Jimma Farmers Cooperative Union and one variety from farmer preserved seed at near Jimma town. The Melko and BH660 seeds were stored with bag, whereas the farmer preserved seed which is unshelled and was hanging over chimney (Figure 1). The treatments of this experiment were six in five replications with completely randomized design (CRD) arrangements.

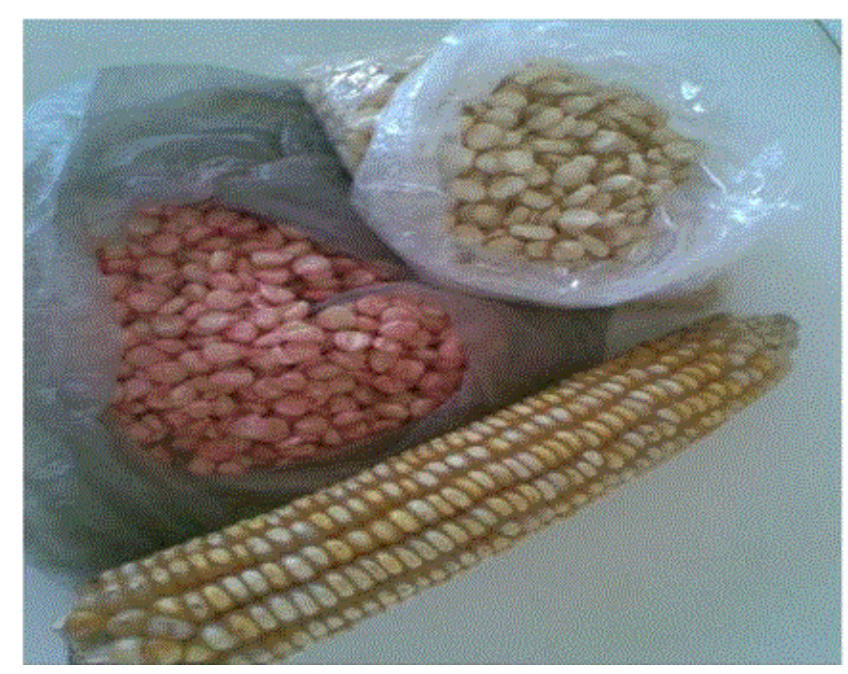

Figure 1: Three maize seed samples collected from different storages at Jimma, Southwestern Ethiopia.

\section{The treatments were}

- $M W 1=$ the variety Melko with surface disinfecting

- $\quad \mathrm{MW} 2=$ the variety Melko without surface disinfecting

- $\mathrm{BH} 660 \mathrm{~W} 1=$ the variety BH660 with surface disinfecting

- $\mathrm{BH} 660 \mathrm{~W} 2=$ the variety $\mathrm{BH} 660$ without surface disinfecting
- $\quad F P S W 1=$ the farmer preserved seed with surface disinfecting

- FPSW2= the farmer preserved seed without surface disinfecting

\section{Maize sampling method}

A total of 3 samples ( $\sim 0.5 \mathrm{~kg}$ of Melko and BH660, and one cob of farmer preserved seed) of maize seeds harvested in 2013 were collected at 3 locations in the Jimma zone around Jimma town, in the maize grain storages of (Jimma Agricultural Research Center, Jimma Zone Jimma Farmers Cooperative Union and Farmer preserved seed at near Jimma town). All five months stored samples were taken from dried maize seed storages.

\section{Incubation tests}

The seeds were incubated for a certain period in the agar plate and blotter test under specific environmental conditions in order to allow pathogens on the seed to grow. Different fungi were identified by features such as the form, length and arrangement of conidiophores, size, septation and chain formation of conidia [22].

\section{Blotter method}

In this method, similar washing and surface disinfecting producers of agar plate were followed. For this method, a total of 250 maize kernels in 5 replication and each replication contained 50 kernels were used. Per subsample, 10 kernels were aseptically placed in each blotter plate which are moistened with sterile distilled water. Then each blotter plats were incubated under ultraviolet light in alternating cycles of 12$\mathrm{h}$ light/darkness for 7 days at $25^{\circ} \mathrm{C}$. Finally each petri dishes (blotter plate) were examined under stero-binocular microscope for fungi isolation based on identification key and each fungal colonies were recorded. In addition to fungal isolation, germination percentage of each blotter were recorded after three and seven days of incubation.

\section{Agar plate method}

For this method, seeds three maize variety kernels with and without surface disinfecting were used and 10 grains of each treatment were aseptically placed on potato dextrose agar (PDA) plate according to McGee [23] procedures. Firstly, from each sample 250 maize kernels; in 5 replications of 50 seeds were selected. To remove the chemical (seed dressants) from the chemically treated seed of BH660, kernels were thoroughly washed in running water. For the surface disinfecting treatments, maize kernel sample was surface disinfected by $1 \%$ Sodium-hypochlorite for one minute and rinsed three times in sterile distilled water for 30 seconds each. From both surface disinfected and non-disinfected samples, 10 kernels per petri plate $(9 \mathrm{~cm}$ diameter plates) containing PDA (potato dextrose agar) were aseptically placed. The plates were incubated at $26^{\circ} \mathrm{C}$ for 7 days and the growth stage of colonies were determined periodically. Finally after 7 days of incubation, the total number of fungal colonies, frequency of isolation of fungi (\%), relative density of isolated fungi (\%) and incidence of fungi (\%) were recorded and calculated.

\section{Incidence of fungi}

Incidence of fungal infection on each sample were calculated by using the following formula:

$$
\underset{\times 100}{\operatorname{In}(\%)}=(\text { Number of infected seeds }) /(\text { Total number of seeds })
$$


where: In = Incidence of fungi

\section{Isolation frequency (IF)}

For each fungus, the proportion of samples that yielded its isolates were determined and expressed as percent by using the following formula [24]:

IF $(\%)=($ Number of samples of occurrence of fungi species $) /$ (Total number of samples) $\times 100$

where: $\mathrm{IF}=$ Isolation frequency

\section{Relative density of fungi}

For each fungus, the relative density of isolated fungal species was calculated by using the following formula[24]:

$\operatorname{Rd}(\%)=($ Number of isolated fungi species $) /$

(Total number of fungi) $\times 100$

where: $\mathrm{RD}=$ Relative density

\section{Seed germination (\%)}

The percentage of kernels that germinated was determined separately for samples from surface disinfected and non-disinfected maize grains on blotter method. The relative reduction for germination also recorded by comparing the relative amount of germination capacity reduced for the varieties. The seed germination was calculated by using the following formula:

$\mathrm{G}(\%)=($ Number of seeds germinated $) /$

(Total number of seeds plated) $\times 100$

where: $\mathrm{G}=$ Seed germination

\section{Statistical analyses}

The germination percentage after 3 and 7 days of incubation and total number of fungal colonies per plate where analyzed by using SAS software version 9.2 software (SAS, 2009) [25] software. Analysis of variance (ANOVA) was performed using general linear model (GLM) procedure.

\section{Result}

\section{Total colony forming units/plate}

In this experimental work, higher significant $(p<0.001)$ difference of total fungal colonies among and within different treatment combinations of the three maize varieties and two surface disinfectant on both agar plate and blotter method was recorded. On agar plate, the highest fungal colony (26-28) followed by (23) fungal colonies was recorded at FPSW2 and FPSW1 respectively. On the other hand, the lowest fungal colony (10) was recorded at BH660W2 which is statistically non-significant with BH660W1 (Table 1). These differences could be due to differences in the storage condition and that of chemical treatment of the seeds. On blotter test the highest fungal colony (6) per plate on MW2 and the lowest fungal colony (1) per plate on MW1 was recorded (Table 1).

In general, on both agar plate and blotter methods significant difference among varieties and with and without surface disinfectant was recorded except on the variety BH660. Very high differences in total fungal colonies were observed between agar plate and blotter methods. This difference could be due to connivance of PDA for easily germination and development of the pathogens on the maize seeds. In this study the high fungal colony development were showed a great redaction on viability of maize seeds (Table 2). This indicates that how much storage fungal pathogens are very important in reducing the viability as well as germination capacity of maize seeds. Which clearly showed that appropriate storage type is critical in increasing both germination percentage of maize seeds and increasing productivity of maize crop.

\begin{tabular}{|l|l|l|}
\hline \multirow{2}{*}{ Treatments } & \multicolumn{2}{|l|}{ Total Fungal Colonies per Plate } \\
\cline { 2 - 3 } & Agar plate & Blotter Test \\
\hline MW1 & $15.0^{\mathrm{d}}$ & $1.4^{\mathrm{d}}$ \\
\hline MW2 & $17.0^{\mathrm{c}}$ & $6.2^{\mathrm{a}}$ \\
\hline BH660W1 & $11.2^{\mathrm{e}}$ & $3.8^{\mathrm{bc}}$ \\
\hline BH660W2 & $9.6^{\mathrm{f}}$ & $3.8^{\mathrm{b}}$ \\
\hline FPSW1 & $23.4^{\mathrm{b}}$ & $2.6^{\mathrm{c}}$ \\
\hline FPSW2 & $27.6^{\mathrm{a}}$ & $3.6^{\mathrm{b}}$ \\
\hline Mean & 17.3 & 3.45 \\
\hline LSD (0.05) & 1.27 & 0.67 \\
\hline CV (\%) & 2.3 & 5.3 \\
\hline
\end{tabular}

Table 1: The total fungal colonies per plate of three maize variety kernels with and without surface disinfecting at agar plate test and blotter test methods. MW1=Melko with surface disinfecting; MW2=Melko without surface disinfecting; $\mathrm{BH} 660 \mathrm{~W} 1=\mathrm{BH} 660$ variety with surface disinfecting; $\mathrm{BH} 660 \mathrm{~W} 2=\mathrm{BH} 660$ variety without surface disinfecting; FPSW1=Farmer preserved seed with surface disinfecting; FPSW2=Farmer preserved seed without surface disinfecting; LSD=Least Significant Difference; CV=Coefficient of Variation; Values following by the same letter within the column or row are not significantly different at 0.05 probability level.

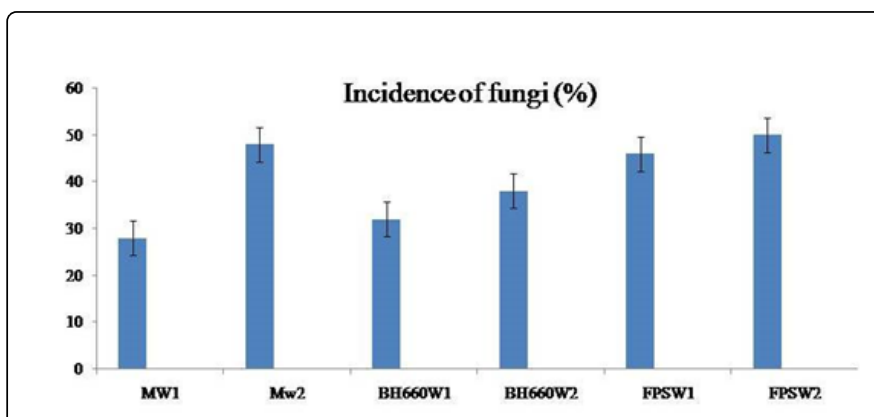

Figure 2: Incidence of fungi on combination of three maize seeds varieties with and without surface disinfection of stored kernels on blotter test.

\section{Fungi incidence associated with maize grain}

A total of 110 fungi isolates were recovered from three maize variety samples in six treatment combinations which is collected in three maize storage conditions, were harvested during 2013 cropping season. 
Page 4 of 6

In this study, $100 \%$ incidences of fungal infection were recorded at all treatments under agar plat. Whereas under blotter test the highest incidences of 50\% were recorded at FPSW2 (farmer preserved seed without surface disinfecting) followed by $48 \%$ and $46 \%$ at MW2 (Melko without surface disinfecting) and FPSW1 (farmer preserved seed with surface disinfecting) respectively (Figure 2).

\section{Frequency of isolation of fungi}

In this experiment the highest frequency of Aspregilus spp. (40.4\%) at farmer preserved seed with surfaclly disinfected kernels followed by $(32 \%)$ on Melko verity which is non-surface disinfected kernels was recorded on agar plate test (Figure 3). The highest frequency of Fusarium spp. (28\%) and Penicilium Spp. (18\%) were recorded both at FPSW2 at agar plate test (Figure 3). In general the highest fungal frequency of the three major storage pathogens of maize was recorded at agar plate method which was placed with farmer preserved seed without surface disinfecting. In blotter test method in all treatments the highest frequency was Aspregilus spp. followed by Fusarium spp. and Penicilium spp. (Figure 4). In this experiment at blotter higher difference of fungal frequency especially on Aspregilus spp. was recorded among kernels which were surfaclly disinfected and that of non-disinfected once (Figure 4). In both agar plate and blotter test methods, a clear difference of fungal frequency of the fungi genera among varieties and their combination with surface disinfection and without disinfection was recorded.

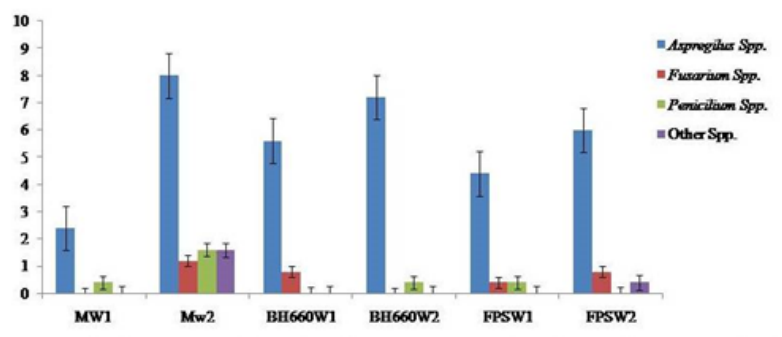

Figure 3: The frequency of fungal pathogens associated with stored maize seeds of three varieties and combined with and without surface disinfecting at Agar plate test.

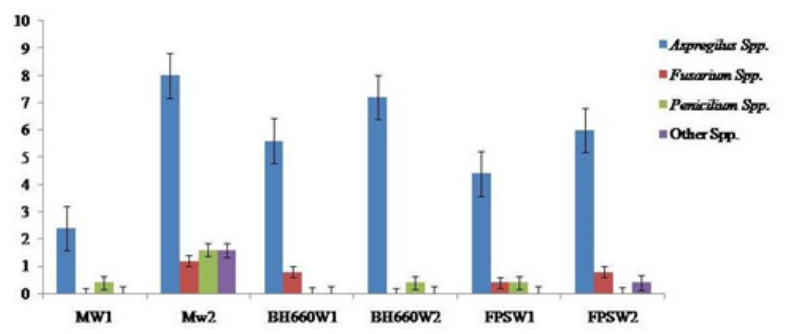

Figure 4: The frequency of fungal panthogens associated with stored maize seeds of three varieties and combined with and without surface disinfecting at Blotter test methods.

\section{Relative density of fungi}

In this experiment the highest relative density of Aspergillus spp. was recorded on both agar plate and blotter test in all treatment combinations except at FPSW2 on agar plate method (Figures 5 and 6). On the other hand, the highest relative density of Fusarium spp. was recorded only at agar plate on the variety farmer preserved seed which is surfaclly non-disinfected. At agar plate test the highest density (99\%) of Aspergillus spp. on MW1 followed by (96\%) on BH660W1 was recorded. The highest Fusarium spp. (51\%) was only recorded at agar plate test on FPSW2. In general the highest fungal relative density of the three most common storage fungi (Aspergillus, Fusarium and Penicilium) were recorded at gar plate on FPSW2 (Figure 6).
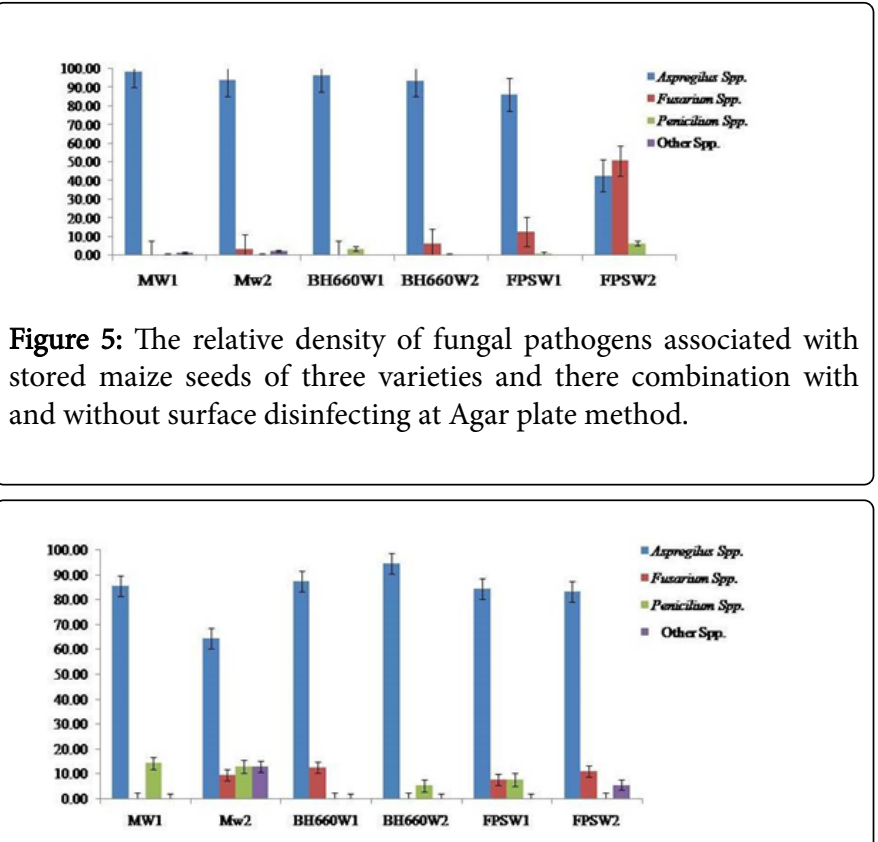

Figure 6: The relative density of fungal pathogens associated with stored maize seeds of three varieties and there combination with and without surface disinfecting at Blotter test method.

\section{Seed viability (\%)}

In this experiment, germination of the three varieties shows significant $(\mathrm{p}<0.001)$ differences among each other's, but there is no significance difference on the same variety which was treated with and without surface disinfection (Table 2) at both 3 and 7 day after incubation on blotter test. The highest seed germination was recorded on MW1, MW2, BH660W2 and FPSW1, whereas the lowest germination (6\% and 62\%) was recorded on FPSW 2 at 3 and 7 days after incubation respectively (Table 2). The total fungal colony and seed viability were showed negative relationships. As total number of fungal colony were increased seed viability were also decreased.

\section{Discussion}

The results of this study were showed that how much the storage fungal pathogens greatly affect the viability of maize seeds. And it is in agreements with the idea of Quezada et al. [26] seed with high rates of fungal infection or insect damage have very low germination rates, 
Page 5 of 6

which can be as low as $28 \%$ of original potential. The results of this study are in agreement with [7] which is in Ethiopia various grain mold fungi including Fusarium, Penicillim, Aspergillus, and Nigropora spp. have been detected on maize samples collected from Hawassa, Areka, Billito, Shallo and Arsi-Negele. The populations of all the fungi were higher in samples collected from farmers' stores than in the samples collected from research and seed multiplication stores. Aspergillus and Fusarium were frequently isolated from stored maize seeds and Penicillim spp. were the second most frequent isolated fungal species. Wubet and Abate [18] also identified four Fusarium species associated with maize grain in Ethiopia.

\begin{tabular}{|l|l|l|}
\hline \multirow{2}{*}{ Treatments } & \multicolumn{2}{|l|}{ Germination (\%) of stored maize kernels on Blotter Test } \\
\cline { 2 - 3 } & After 3 Days of Incubation & 7 Days of Incubation \\
\hline MW1 & $48^{\mathrm{a}}$ & $84^{\mathrm{ab}}$ \\
\hline MW2 & $42^{\mathrm{a}}$ & $88^{\mathrm{a}}$ \\
\hline BH660W1 & $18^{\mathrm{b}}$ & $76^{\mathrm{b}}$ \\
\hline BH660W2 & $18^{\mathrm{b}}$ & $84^{\mathrm{ab}}$ \\
\hline FPSW1 & $12^{\mathrm{bc}}$ & $80^{\mathrm{ab}}$ \\
\hline FPSW2 & $6^{\mathrm{c}}$ & $62^{\mathrm{c}}$ \\
\hline Mean & 24 & 79 \\
\hline LSD (0.05) & 6.8 & 9.48 \\
\hline CV (\%) & 11.6 & 5.7 \\
\hline
\end{tabular}

Table 2: Germination percentage of three maize varieties and their combinations with and without surface disinfecting at 3 and 7 days after incubation on blotter test. MW1=Melko with surface disinfecting; MW2=Melko without surface disinfecting; $\mathrm{BH} 660 \mathrm{~W} 1=\mathrm{BH} 660$ variety with surface disinfecting; $\mathrm{BH} 660 \mathrm{~W} 2=\mathrm{BH} 660$ variety without surface disinfecting; FPSW1=Farmer preserved seed with surface disinfecting; FPSW2=Farmer preserved seed without surface disinfecting; LSD=Least Significant Difference; CV=Coefficient of Variation; Values following by the same letter within the column or row are not significantly different at 0.05 probability level.

The present study were identified three major genera of fungi that associated with stored maize seed in Jimma, southwestern Ethiopia. Our result agree with Orsi et al. [11] and Samson [27] reports, which are the major genera commonly encountered on maize grain in tropical regions are Fusarium, Aspergillus and Penicillium. The development of these fungi can be affected by moisture content of the product [13], temperature, storage time and degree of fungal contamination prior to storage, insect and mite activity facilitate fungi dissemination [8]. During storage, several kinds of fungi can remain associated to corn seeds either causing their deterioration or simply remain viable to infect germinating seedling. The fungi genera typically found in stored grains are Aspergillus, Penicillium, Fusarium and some xerophytic species, several of them with capabilities of producing toxins [12]. Aspergillus, Fusarium, Penicillium and Cladosporium are the predominant fungal genera associated with grain in storage [28]. $A$. flavus can infect maize pre- and post-harvest and an increase in aflatoxin content can occur if the phases of drying and storage are poorly managed [29]. Several phytopathogenic species of Fusarium are found to be associated with maize including $F$ verticillioides, $F$. proliferatum, F graminearum and $F$ anthophilum [30,31].
Fungi from five genera (Aspergillus, Fusarium, Penicillium, Alternaria and Calviceps) are responsible for the production of the great majority of the mycotoxins that are of agricultural relevance [32]. The losses caused by seed fungi may occur during seed development, storage or germination. Damage may result from loss of seed viability or from seedling infection following germination [33]. Fusarium, Aspergillus and Penicillium were the most common genera isolated from maize seed samples collected around Shashemene and Alemaya [34-36]. The researchers found three toxic species of Fusarium (F. moniliforme, $F$. subglutinans, and $F$ graminearum) to be highly associated with maize samples. A previous survey by Abate [37] also indicated that Fusarium was the most common genus in maize grain samples. Therefore, farther studies are needed for identification of the major storage fungal pathogens that greatly affect viability of maize seeds and their management options.

\section{Conclusion}

All maize seeds collected from different storage structures are highly infested with a number of fungal seed borne pathogens and this can affect germination capacity of the seed. Seed selection is useful in improving seed germination and reducing the seed borne spectrum of most pathogens of maize. Aspergillus spp. are the most dominant storage fungi followed by Fusarium spp. were isolated in this study. These fungi are important accurate detections and identifications along with viability tests before supplying seeds to farmers are crucial in order to develop an appropriate management strategies. In Ethiopia there is a great gap of experiments on stored maize seed pathogens. So, giving attentions to these pathogens may play a vital role in the country's development and transformation strategy.

\section{Acknowledgement}

We would like to express our grateful thank to the Jimma Agricultural Research Center, the Jimma Zone Farmers Cooperative Union and the farmer who lives around Jimma town for their seed supply. We are also thankful to the Jimma University College of Agriculture and Veterinary Medicine, Plant Pathology Laboratory for material and consumable supplies.

\section{References}

1. Kyenpia EO, Namo, OAT, Gikyu SW, Ifenkwe OP (2009) A comparative study of the biochemical composition of some varieties of maize (Zea mays) grown in Nigeria. Nigeria Journal of Botany 22: 291-296.

2. International Institute for Tropical Agriculture (IITA) (2005) Annual report 3: 20-32.

3. Ortiz R, Taba S, Chavez VH, Tovar M, Mezzalama Y, et al. (2010) Conserving and Enhancing Maize Genetic Resources as Global Public Goods- A Perspective from CIMMYT. Crop Science 50: 13-28.

4. Rosegrant MW, Msangi S, Ringler C, Sulser TB, Zhu T, et al. (2008) International Model for Policy Analysis of Agricultural Commodities and Trade (IMPACT): Model Description. International Food Policy Research Institute Washington DC.

5. Central Statistical Agency (CSA) (2015) The Federal Democratic Republic of Ethiopia Agricultural Sample Survey 2014/2015 (2007 E.C.).Volume I, Report on Area and Production of Major Crops(Private Peasant Holdings, Meher Season).

6. Carlos DL (1984) Maize disease. A guide for field identification CIMMYT.

7. Tegegne G, Abebe F, Hussien T, Tilahun T, Belete E, et al. (2009) Review of Maize, Sorghum and Millet Pathology Research. In: "Increasing Crop Production through Improved Plant Protection-Volume II." (A. Tadesse. 
Citation: Tsedaley B, Adugna G (2016) Detection of Fungi Infecting Maize (Zea mays L.) Seeds in Different Storages Around Jimma, Southwestern Ethiopia. J Plant Pathol Microbiol 7: 338. doi:10.4172/2157-7471.1000338

Page 6 of 6

Eds.). Plant Protection Society of Ethiopia (PPSE). PPSE and EIAR, Addis Ababa.

8. Suleiman MN, Omafe OM (2013) Activity of three medicinal plants on fungi isolated from stored maize seeds (Zea mays (L). Global Journal of Medicinal Plant Research 1: 77-81.

9. Ominski KH, Marquardt RR, Sinha RN, Abramson D (1994) Ecological aspects of growth and mycotoxin production by storage fungi. Miller JD Trenholm HL (Eds) Mycotoxins in grains Compounds other than aflatoxin Eagen Press USA pp: 287-305.

10. Kossou DK, Aho N (1993) Stockage et conservation des grains alimentaires tropicaux: principes et pratiques. Les Editions du Flamboyant Benin 125.

11. Orsi RB, Correa B, Possi CR, Schammass EA, Noguerira JR, et al. (2000) Mycoflora and occurrence of fumonisins in freshly harvested and stored hybrid maize. Journal of Stored Product Research 36: 75-87.

12. Castlellarie C, Marcos FV, Mutti J, Cardoso L, Bartosik R (2010) Toxigenic fungi in Corn (Maize) stored in hermetic plastic bags. National institute of agricultural Technologies Mardel Plata University Argentina pp: 115-297.

13. Gtorni P, Battilani P, Magan N (2009) Effect of solute and matric potential on in- vitro growth and sporulation of strains from anew population of Aspergillus flavus in Italy. Fungi Ecology 1: 101-106.

14. Lerda P, Blaggi BM, Peralta N, Ychari S, Vazquez M, et al. (2005) Fumonisins in foods from Cordoba (Argentina), presence and genotoxicity. Food and Chemical Toxicology 43: 691-698.

15. Voss KA, Smith GW, Haschek WM (2007) Fumonisins: toxicokinetics, mechanism of action and toxicity. Animal feed science and technology 137: 299-325.

16. Uzma S, Shahida A (2007) The screening of seven medicinal plants for artificial activity against seed borne fungi of maize seeds. Pakistan Journal of Botany 39: 285-292.

17. Charity A, Amienyo J, Dauda T (2010) Effect of relative humidity on spore germination and growth of Aspergillus flavus. Nigerian Journal of Botany 23: 1-6.

18. Wubet T, Abate D (1998) Toxigenic Fusarium species in maize grain in Ethiopia. Proceedings of the 6th Eastern and Southern Africa Regional Maize Conference CIMMYT/EARO.

19. Geyed A, Maru A (1987) A survey of Aflatoxin content in Maize, sorghum and tef samples. Ethiopian Journal of health Dev 2: 59-70.

20. Abate D, Abegaz BG (1985) Prevalence of aflatoxin in Ethiopia on cereal grain. A preliminary Survey in Ethiopia. Medical Journal 23: 143-148.

21. Ibrahim O (2008) Cooperatve Community Based Seed Enterprise in Haraghe Ethiopia. Case Study from Farmer, Seeds, Varietes: Supporting Informal Seed Supply in Ethiopia.
22. Warham EJ, Butler LD, Sutton BC (1990) Seed testing of maize and wheat: A Laboratory Guide. CYMMYT CAB International UK pp: 84.

23. McGee DC (1994) Seed assays for Stewart's wilt and other seed-borne disease of corn. Proceedings of Annual Corn Sorghum Reseroh Conflerence 48: 161-168

24. Marasas WFO, Burgess LW, Anelich RY, Lamprecht SC, van Schalkwyk DJ (1988) Survey of Fusarium species associated with plant debris in South African soils. S African Journal of Botany 54: 63-71.

25. SAS Inc (2008) SAS Guide for Personal Computers. SAS Institute Cary NC.

26. Quezada MY, Moreno J, Vazquez ME, Mendoza M, Mendex-Albores A, et al. (2006) Hermetic storage system preventing the proliferation of Prostephanus truncatus Horn and storage fungi in maize with different moisture contents. Postharvest Biology and Technology 39: 321-326.

27. Samson RA (1991) Identification of food-borne Penicillium, Aspergillus and Fusarium species. Fungi and Mycotoxins in Stored Products 23: 39.

28. Ames (2003) Iowa Council for Agricultural Science and Technology Mycotoxins: risks in plant, animal and human systems USA.

29. Chulze SN (2010) Strategies to reduce mycotoxin levels in maize during storage: a review. Food Additives and Contaminants 27: 651-657.

30. Munkvold GP, Desjardins AE (1997) Fumonisins in maize. Can we reduce their occurrence? Plant Disease 81: 556-564.

31. Scott PM (1993) Fumonisins. Int J Food Microbiology 18: 257-270.

32. Jones BD, Toal ME (2003) Mycotoxins in food: a UK regulatory perspective. Aspects Applied Biology 68: 1-9.

33. Suleiman MN, Omafe OM (2013) Activity of Three Medicinal Plants on Fungi Isolated From Stored Maize Seeds. Global Journal of Medicinal Plant Research 1: 77-81.

34. Wubetu T (1997) Fusarium and Fusarium toxins in maize in some regions of Ethiopia. Addis Ababa University.

35. Wubet T, Abate D (1999) Toxigenic Fusarium species in Maize grain in Ethiopia. Maize production Technology for the future: Challenges and opportunities: Proceedings of the six eastern and southern Africa Regional Maize Conference 132-134.

36. Wubetu T, Abate D (2000) Common toxigenic Fusarium species in maize grain in Ethiopia. SINET Ethiopian Journal of Science 23: 73-86.

37. Abate D (1982) A preliminary study of the fungal flora of Ethiopian cereal grains with special emphasis on the prevalence of toxigenic groups. Addis Ababa Ethiopia. 